\title{
Composition of Refuse Derived Fuels in Latvia and Estonia in Comparision with Worldwide Average Values
}

\author{
Dmitry Porshnov \\ Department of Environmental Sciences, \\ University of Latvia \\ Riga, Latvia \\ dmitrijs.porsnovs@lu.lv
}

\author{
Dace Arina \\ Institute of Phisical Energetics of Latvia \\ Riga, Latvia \\ dace.arina@gmail.com
}

\author{
Maris Klavins \\ Department of Environmental Sciences, \\ University of Latvia \\ Riga, Latvia \\ maris.klavins@lu.lv
}

\begin{abstract}
Information about composition of RDF worldwide was collected using literature analysis. RDF samples produced in Latvia and Estonia were collected, those fractional and elemental composition analyzed using standard methods. Comparing obtained results with worldwide data we have found that the quality of local RDFs in general is higher than typical values, while elevated content of chlorine must be mentioned as a problem. Results also show that majority of chlorine in studied samples exists in organic form. Recommendations to overcome this problem have been developed.
\end{abstract}

Keywords-RDF, SRF, quality, Latvia, Estonia.

\section{INTRODUCTION}

Waste is a resource that still must be considered as strongly underused in Baltic states. Refuse derived fuels (RDF) is the light fraction of solid wastes enriched in organic content and calorific value using multiple technical approaches, such as manual sorting, screening, sorting by air stream etc. Use of RDF not only reduces amounts of waste that requires landfilling, but also might be a source of energy that is free of charge or even have a negative value. It is estimated, that in the case of Latvia, use of RDF could replace imported fossil resources and cover up to $3.5 \%$ of states total energy needs [1]. The main consumers of RDF today are cement plants, sometimes this fuel might be used in traditional energetics as well, while cement plants have strict quality requirements, that are not always easy executable for waste management companies, while simple incineration with lower quality requirements is undesirable, not only from the point of view of environmental pollution, but also considering the need to bring our economies closer to the concept of circular material flows. Development of novel waste management approaches, based on pyro-gasification technologies is needed to implement mentioned concepts. Deep understanding of the composition of feedstock in the case of pyro-gasification is much more important than in the case of simple incineration [2].

In our study we have defined typical composition of $\mathrm{RDF}$, by using data from worldwide scientific literature.
RDF produced by different waste management companies in Latvia and Estonia have been analysed, using standardised physically-chemical methods, composition of these fuels established. Valuable information about strengths and deficiencies of analysed fuels as well as about reasons of these qualities have been got by comparison of obtained values with typical composition.

\section{Materials and Methods}

Samples of RDF were collected in 4 RDF processing facilities in Latvia (the names of facilities are not disclosed; results are presented only after statistical treatment). Collection of samples performed after the shredder (or after biotreatment in cases of Estonian samples). In every factory, 20 samples (around $1 \mathrm{~kg}$ each) taken and then mixed together. Moisture of samples detected using drying at $105^{\circ} \mathrm{C}$ (Standard method CEN/ TS 15414-2:2006). Fractional composition characterized using manual sorting: $1 \mathrm{~kg}$ of sample in 5 replicates have been sorted, results averaged. Elemental composition analyzed using standard methods: calorific value EN ISO 18125, sulphur and chlorine content LVS EN ISO 16994, nitrogen, carbon and hydrogen content LVS EN ISO 16948, oxygen content calculated. Proximate analysis made using thermogravimetric method described in [3].

Composition data of RDF outside Baltic states was collected using literature review method. Typical fractional composition estimated using the data provided in [4]-[10]. Typical elemental composition, proximate composition and calorific values were estimated based on data provided in [9]-[29] geographically covering industrial countries of Europe, North America and Asia.

\section{RESULTS AND DISCUSSION}

As we see on the Figure 1., fractional composition of RDF in Baltics differs strongly from typical worldwide values. The most important differences are related with the content of plastic and lignocellulose (paper cardboard and wood) fractions. Content of lignocellulosic wastes in RDFs collected in Baltics is approximately two times 
lower than typical values found in literature, while content of plastics is about 2 times higher. Content of food fraction in Baltic RDFs is significantly lower, than average. The main qualitative characteristic of RDF: its heating values (HV) in Latvia
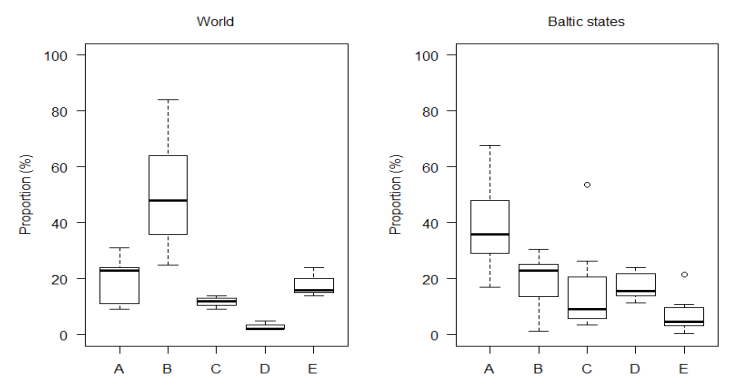

$$
\begin{aligned}
& \text { Legend: } \\
& \text { A: Plastics } \\
& \text { B: Paper, cardboard and wood } \\
& \text { C: Textiles } \\
& \text { D: Other coarse compounds } \\
& \text { E: Food wastes and fine fraction }
\end{aligned}
$$

Figure 1. Fractional composition of RDF in studied samples compared with the typical values.
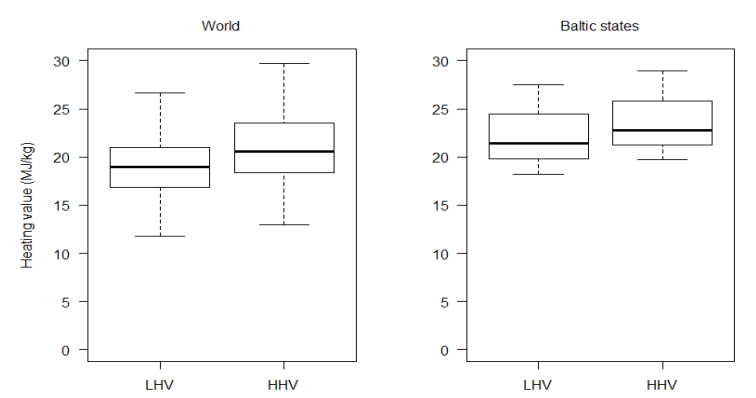

Figure 2. Comparision of calorific values of studied samples with the

$$
\text { typical values. }
$$

and Estonia are significantly $(\approx 3 \mathrm{MJ} / \mathrm{kg}$ ) higher (Figure

2.) than it is typical worldwide. Taking into account, that plastic fraction is the one with the highest $\mathrm{HV}$, while lignocellulosic fraction shows lower HV [9], this fact may be explained with the first finding of this study.

Analysis of the content of main organic elements (Figure 3.) show that the content of carbon in studied fuels must be considered very high: this element constitutes up to $65 \%$ of studied fuels: much more than average typical value $(\approx 50 \%)$. Content of oxygen show opposite tendencies: its value is under $20 \%$, while typical values are around $30 \%$. Hydrogen content in studied samples is slightly higher than typical values. Also these differences arise from dissimilarities in fractional composition. Fossil based materials, such as plastics are the main sources of carbon and hydrogen, while oxygen dominantly is supplied by cellulose based materials such as paper and cardboard [29]. Analysis of the content of undesirable nonmetallic elements (Figure 4) shows that values of nitrogen and sulphur content are absolutely typical, while content of chlorine is 3 times higher than typical values. Chlorine, is a key element causing high temperature corrosion in Waste to Energy plants based on incineration [30], as well as on gasification [31]. Chlorine also must be considered as the most serious issue regarding the use of RDF in
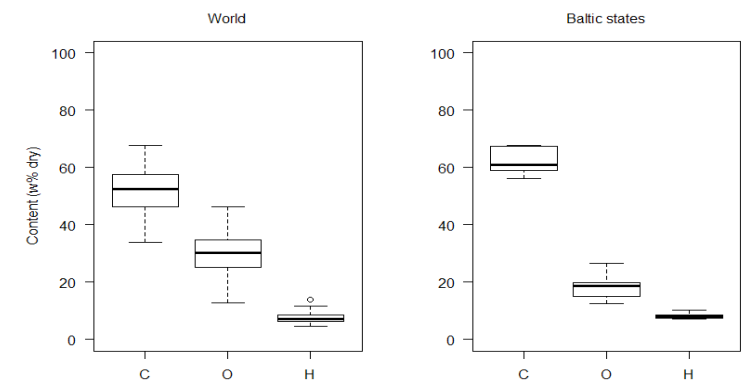

Figure 3 Comparison of the content of main elements in studied samples with the worlwide literature data.
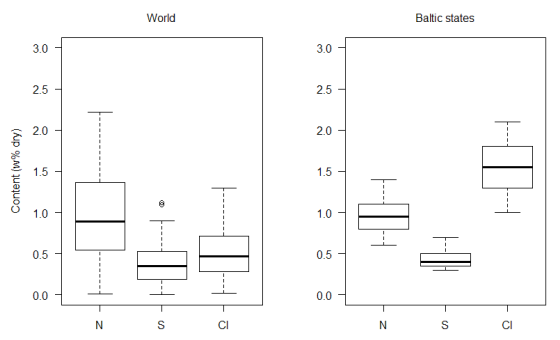

Figure 4. Comparison of the content of undesirable non-metalic elements in studied samples with typical values.

cement kilns, since it weakens the cement and causes the corrosion of steel bars in reinforced concrete [32]. The main source of organic chlorine in RDF is the nonpackaging plastics fraction, while the dominating sources of the inorganic chlorine are fractions of food and garden wastes [30]. Typically, around one half of the chlorine content comes from poly(vinyl chloride) (PVC), while the second half are chlorides of alkali metals coming from organic waste [33]. Taking into account that ratio of food waste and plastic fractions in studied materials are not typical, it may be concluded, that absolute majority of chlorine in RDFs produced in Latvia and Estonia is organic and is arising

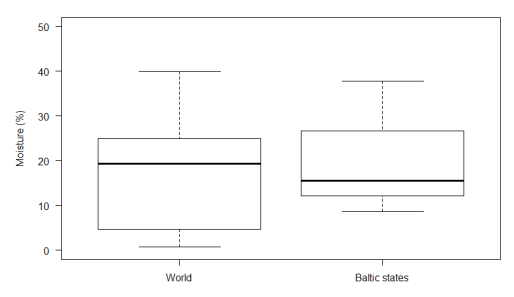

Figure 5. Comparison of moisture content (as received) of studied RDFs with typical values worldwide.
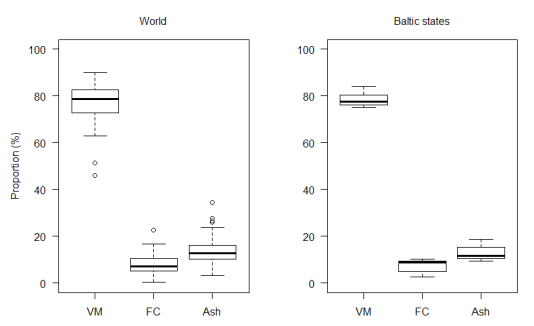

Figure 6. Comparison of proximate composition (dry) of studied samples with typical values. 
from high PVC content in plastic fraction. They are multiple ways to dissolve this problem. As it was pointed by [34], one way is to supplement the pre-treatment system with sorting by means of near-infrared spectroscopy (NIR) to reduce the share of PVC directly. The second way is indirect reduction of PVC content by increasing recovery of fractions low in chlorine (such as paper and cardboard), or by addition of biomass with low chlorine content. Decrease of calorific value and increase of moisture must be mentioned as the main disadvantages of this way. The third possible approach is a low temperature thermal treatment of RDFs known as torrefaction, mild pyrolysis or destructive drying. Torrefaction as an approach useful for upgrading low quality waste derived fuels received a wide attention from the scientific community in last years [35]-[37], and was showed to be highly effective for increasing attractiveness of RDF as energy source. The effects of torrefaction include increase of grindability due to disappearance of fibrous structures, [36], increase of heating value and improvement of combustion characteristics [35]-[37], significant decrease in chlorine content [35]-[36], reduction in the oxygen content, increase in the carbon content [35], as well as significant decrease of heterogeneity [36]. Fuel obtained as a result of RDF torrefaction shows better fuel characteristics than coal. Dechlorination in the process of torrefaction is explained with conversion of organic chlorine to $\mathrm{HCl}$ and evaporation of acid [38], thence it may be direct solution for the observed problem. Torrefaction may be used as separate pre-treatment stage, bus as well may be incorporated into two staged pyrolysis-gasification process.

As it is shown on Figures 5-6, contrary to elemental composition, proximate composition of studied RDFs may be considered as absolutely typical.

\section{CONCLUSIONS}

Fractional composition of RDFs produced in Latvia and Estonia differ from typical values. It is characterised by significantly higher content of plastics as well as lower content of cellulose. This fact results not only in highquality features of studied fuels, such as high calorific value, hydrogen and carbon content, but also in significant problem: high chlorine, that make this fuel/feedstock almost unusable. Differences in ratios of plastic fraction and food waste fraction in comparison with typical RDF composition, clearly show that absolute majority of the chlorine in studied materials is organic.

\section{ACKNOWLEDGEMENTS}

This work has been supported by the European Regional Development Fund within the project No. 1.1.1.1/16/A/050 "Variable fuel gasification for municipal solid waste recovery".

\section{REFERENCES}

[1] E. Dace, and D. Blumberga, An assessment of the potential of refuse-derived fuel in Latvia. Manag. Environ. Qual. Int. J. vol. 235), pp. 503-516, 2012. https://doi. org/10.1108/14777831211255088

[2] D. Porshnov, V. Ozols, L. Ansone-Bertina, J. Burlakovs, and M. Klavins, "Thermal decomposition study of major refuse derived fuel components," Energy Procedia, vol. 147, pp. 48-53, 2018 https://doi.org/10.1016/j.egypro.2018.07.032

[3] R. K. Agrawal, "A Rapid Technique for Characterization and Proximate Analysis of Refuse-Derived Fuels and Its Implications for Thermal Conversion," Waste Management \& Research, vol. 6, no. 1, pp. 271-280, 1988. https://doi. org/10.1177/0734242x8800600143

[4] P. Makkonen, A. Hotta. "Experiences of RDF fluidized-bed combustion and gasification, emissions and fuel quality aspects", presented at Power production from waste and biomass: Advanced concepts and technologies, Espoo, Finland, 2002.

[5] G. Tchobanoglous, H. Theisen, and S. Vigil, Integrated solid waste management: engineering principles and management issues. New York: McGraw-Hill., 2004

[6] Gendebien, A. Leavens, A. Godley, "Refuse derived fuel, current practice and perspectives". European Commission - Directorate General Environment Final Report B43040/2000/306517/MAR/E3, 2003. [Online]. Available: European Commission: http://ec.europa.eu/environment/ waste/studies/pdf/rdf.pdf [Accessed April 01, 2019]

[7] [7] Papageorgiou, A. Karagiannidis, J. R. Barton, and E. Kalogirou, "Municipal solid waste management scenarios for Attica and their greenhouse gas emission impact," Waste Management \& Research, vol. 27, no. 9, pp. 928-937, 2009.

[8] https://doi.org/10.1177/0734242x09350787

[9] P. S. Calabrò, "The effect of separate collection of municipal solid waste on the lower calorific value of the residual waste," Waste Management \& Research, vol. 28, no. 8, pp. 754-758, 2009. https://doi.org/10.1177/0734242x09351907

[10] C. Montejo, C. Costa, P. Ramos, and M. D. C. Márquez, "Analysis and comparison of municipal solid waste and reject fraction as fuels for incineration plants," Applied Thermal Engineering, vol. 31, no. 13, pp. 2135-2140, 2011. https://doi.org/10.1016/j.applthermaleng.2011.03.041

[11] A. Gallardo, M. Carlos, M. Bovea, F. J. Colomer, and F. Albarrán, "Analysis of refuse-derived fuel from the municipal solid waste reject fraction and its compliance with quality standards," Journal of Cleaner Production, vol. 83, pp. 118-125, 2014. https://doi.org/10.1016/j. jclepro.2014.07.085

[12] N. Magasiner, and J. W. de Kock, (1987). Design criteria for fibrous fuel fired boilers. Energy world, vol. 150, pp. 4-12, 1987.

[13] P.K. Herbert, L. Baguss, and J. C. Loeffler, "Low-Btu gas from bark and waste via CFB gasification," Energy from biomass and wastes, vol 7, pp. 731-751, 1989.

[14] O. Kitani, Biomass handbook. New York, NY: Gordon and Breach Science Publ., 1989.

[15] J. H. Canova and D. J. Bushnell, "Testing and evaluating the combustion characteristics of densified RDF and mixed waste paper," Energy from Biomass and Wastes, vol. 16, pp. 1191-1191, 1993.

[16] M. L. Murphy, "Integrated Recycling, Resource Recovery, and Energy Facility: The Experience at Louisville, Kentucky". Energy from Biomass and Wastes, vol. 16, pp. 1257-1257, 1993

[17] T. Abbas, P. Costen, F.C. Lockwood and J.J Ou.: "Co-firing refuse derived fuel (RDF) with fossil fuels in a large-scale laboratory furnace" presented at International Flame Days, Clean combustion of waste and non-conventional fuels, Biarritz, France, 1994.

[18] P. Costen, F. C. Lockwood and J. J. Ou: Analysis of solid waste fuels, APAS Clean Coal Technology, London (UK), Imperial College of Science, Technology and Medicine, 
EUcontract CT92-0002, 32 p. (1994).

[19] R. Venendaal, Gasification of waste. Evaluation of the Thermoselect and TPS / Greve installations, Energy recovery from waste and biomass. BTG, KEMA en VVAV, Novem-EWAB no. 9407, 114 p. 1994 (in Dutch). Vergassing van afval. Evaluatie van de installaties van Thermoselect en TPS/Greve, Energiewinning uit afval en biomassa, Utrecht, BTG, KEMA en VVAV, Novem-EWAB no. 9407, 114 p. 1994

[20] T. R. Miles, Alkali deposits found in biomass power plants. Golden, CO: National Renewable Energy Laboratory, 1996.

[21] M. Öhman and A. Nordin, "A New Method for Quantification of Fluidized Bed Agglomeration Tendencies: A Sensitivity Analysis," Energy \& Fuels, vol. 12, no. 1, pp. 90-94, 1998, https://doi.org/10.1021/ef970049z

[22] A. Garg, R. Smith, D. Hill, N. Simms, and S. Pollard, "Wastes as Co-Fuels: The Policy Framework for Solid Recovered Fuel (SRF) in Europe, with UK Implications," Environmental Science \& Technology, vol. 41, no. 14, pp. 4868-4874, 2007 https://doi.org/10.1021/es062163e

[23] G. Dunnu, J. Maier, and G. Scheffknecht, "Ash fusibility and compositional data of solid recovered fuels," Fuel, vol. 89, no. 7, pp. 1534-1540, 2010, https://doi.org/10.1016/j. fuel.2009.09.008

[24] S. Wagland, P. Kilgallon, R. Coveney, A. Garg, R. Smith, P. Longhurst, S. Pollard, and N. Simms, "Comparison of coal/ solid recovered fuel (SRF) with coal/refuse derived fuel (RDF) in a fluidised bed reactor," Waste Management, vol. 31, no. 6, pp. 1176-1183, 2011, https://doi.org/10.1016/j. wasman.2011.01.001

[25] O. N. Kimambo and P. Subramanian, "Energy efficient refuse derived fuel (RDF) from municipal solid waste rejects: a case for Coimbatore," International Journal of Environment, vol. 3, no. 2, pp. 205-215, 2014, https://doi. org/10.3126/ije.v3i2.10530

[26] J. Kluska, M. Klein, P. Kazimierski, and D. Kardaś, "Pyrolysis of biomass and refuse-derived fuel performance in laboratory scale batch reactor," Archives of Thermodynamics, vol. 35 , no. 1, pp. 141-152, 2014, https://doi.org/10.2478/ aoter-2014-0009

[27] Michał Kuna, "Analysis of thermal conversion of non-homogeneous solid recovered fuels," M.S. thesis, Technical University of Lisboa, Lisboa, Portugal, 2015. . [Online]. Available: Technical University of Lisboa https://fenix. tecnico.ulisboahttps://fenix.tecnico.ulisboa.pt/downloadFile/1126295043833896/Dissertation.pdf.pt/downloadFile/1126295043833896/Dissertation.pdf [Accessed April 01, 2019]

[28] S. Akdağ, A. Atımtay, and F. Sanin, "Comparison of fuel value and combustion characteristics of two different RDF samples," Waste Management, vol. 47, pp. 217-224, 2016, https://doi.org/10.1016/j.wasman.2015.08.037
[29] H. Haykiri-Acma, G. Kurt, and S. Yaman, "Properties of Biochars Obtained from RDF by Carbonization: Influences of Devolatilization Severity," Waste and Biomass Valorization, vol. 8, no. 3, pp. 539-547, 2016, https://doi. org/10.1007/s12649-016-9610-5

[30] T. Khosasaeng and R. Suntivarakorn, "Effect of Equivalence Ratio on an Efficiency of Single Throat Downdraft Gasifier Using RDF from Municipal solid waste," Energy Procedia, vol. 138, pp. 784-788, 2017, https://doi. org/10.1016/j.egypro.2017.10.066

[31] M. Materazzi, "Clean energy from waste: fundamental investigations on ashes and tar behaviours in a two stage fluid bed-plasma process for waste gasification," $\mathrm{PhD}$ dissertation, University College, London. UK 2015.

[32] W. Ma, G. Hoffmann, M. Schirmer, G. Chen, and V. S. Rotter, "Chlorine characterization and thermal behavior in MSW and RDF," Journal of Hazardous Materials, vol. 178, no. 1-3, pp. 489-498, 2010, https://doi.org/10.1016/j. jhazmat.2010.01.108

[33] W. Bakker, "High temperature corrosion in gasifiers," Materials Research, vol. 7, no. 1, pp. 53-59, 2004, https:// doi.org/10.1590/s1516-14392004000100009

[34] N. Chatziaras, C. S. Psomopoulos, and N. J. Themelis, "Use of waste derived fuels in cement industry: a review," Management of Environmental Quality: An International Journal, vol. 27, no. 2, pp. 178-193, 2016, https://doi. org/10.1108/MEQ-01-2015-0012

[35] Buekens and K. Cen, "Waste incineration, PVC, and dioxins," Journal of Material Cycles and Waste Management, vol. 13, no. 3, pp. 190-197, 2011, https://doi.org/10.1007/ s10163-011-0018-9

[36] D. Arina and A. Orupe, "Characteristics of mechanically sorted municipal wastes and their suitability for production of refuse derived fuel," Scientific Journal of Riga Technical University. Environmental and Climate Technologies, vol. 8, no. -1, pp. 18-23, 2012, https://doi.org/10.2478/v10145012-0003-0

[37] H. Yuan, Y. Wang, N. Kobayashi, D. Zhao, and S. Xing, "Study of Fuel Properties of Torrefied Municipal Solid Waste," Energy \& Fuels, vol. 29, no. 8, pp. 4976-4980, 2015, https://doi.org/10.1021/ef502277u

[38] A. Białowiec, J. Pulka, P. Steppień, P. Manczarski, and J. Gołaszewski, "The RDF/SRF torrefaction: An effect of temperature on characterization of the product - Carbonized Refuse Derived Fuel," Waste Management, vol. 70, pp. 91100, 2017, https://doi.org/10.1016/j.wasman.2017.09.020

[39] Z. Xu, S. Zinchik, S. S. Kolapkar, E. Bar-Ziv, T. Hansen, D. Conn, and A. G. Mcdonald, "Properties of Torrefied U.S Waste Blends," Frontiers in Energy Research, vol. 6, 2018, https://doi.org/10.3389/fenrg.2018.00065

[40] J. Yu, L. Sun, C. Ma, Y. Qiao, and H. Yao, "Thermal degradation of PVC: A review," Waste Management, vol. 48, pp. 300-314, 2016, https://doi.org/10.1016/j.was$\underline{\text { man.2015.11.041 }}$ 